Open Access

\title{
Smoking and nasopharyngeal carcinoma mortality: a cohort study of 101,823 adults in Guangzhou, China
}

Jia-Huang Lin ${ }^{1}$, Chao-Qiang Jiang ${ }^{2}$, Sai-Yin Ho ${ }^{1}$, Wei-Sen Zhang ${ }^{2}$, Zhi-Ming Mai ${ }^{1}$, Lin Xu' ${ }^{1}$ Ching-Man Lo ${ }^{\text {* }}$ and Tai-Hing Lam ${ }^{1}$

\begin{abstract}
Background: Nasopharyngeal carcinoma (NPC), also known as Cantonese cancer, is rare worldwide, but has particularly high incidence in North Africa and Southeast Asia, especially in Guangdong, China, such as Guangzhou. Tobacco causes head and neck cancers, but nasopharyngeal carcinoma is not included as causally related to smoking in the 2014 United States Surgeon General's report. Prospective evidence remains limited. We used Guangzhou Occupational Cohort data to conduct the first and robust prospective study on smoking and NPC mortality in an NPC high-risk region.

Methods: Information on demographic characteristics and smoking status was collected through occupational health examinations in factories and driver examination stations from March 1988 to December 1992. Vital status and causes of deaths were retrieved until the end of 1999. Cox proportional hazard model was used to assess the association of smoking with NPC mortality.

Results: Of 101,823 subjects included for the present analysis, 34 NPC deaths occurred during the average 7.3 years of follow up. The mean age (standard deviation) of the subjects was 41 (5.7) years. Compared with never smokers, the hazard ratio (HR) of NPC mortality was 2.95 (95\% confidence interval 1.01-8.68; $p=0.048$ ) for daily smokers and 4.03 (1.29-12.58; $p=0.016)$ for smokers with more than 10 pack-years of cumulative consumption, after adjusting for age, sex, education, drinking status, occupation and cohort status and accounting for smoking-drinking interaction. The risk of NPC mortality increased significantly with cigarettes per day ( $p$ for trend $=0.01$ ) and number of pack-years ( $p$ for trend $=0.02$ ).

Conclusions: In this first and largest cohort in a high NPC risk region, smoking was associated with higher NPC mortality. The findings have shown statistically significant dose-response trend between smoking amount and smoking cumulative consumption and the risk of NPC mortality, but due to the small event number, further studies with larger sample size are needed to confirm the findings in the present study. Our results support that smoking is one of the risk factors likely to be causally associated with NPC mortality.
\end{abstract}

Keyword: Nasopharyngeal carcinoma, Smoking, Guangzhou Occupational Cohort, Chinese

\footnotetext{
* Correspondence: lomaggie@hku.hk

${ }^{1}$ School of Public Health, University of Hong Kong, No 21 Sassoon Road,

Hong Kong, China

Full list of author information is available at the end of the article
}

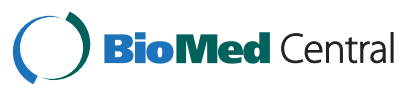

(C) 2015 Lin et al. Open Access This article is distributed under the terms of the Creative Commons Attribution 4.0 International License (http://creativecommons.org/licenses/by/4.0/), which permits unrestricted use, distribution, and reproduction in any medium, provided you give appropriate credit to the original author(s) and the source, provide a link to the Creative Commons license, and indicate if changes were made. The Creative Commons Public Domain Dedication waiver (http://creativecommons.org/publicdomain/zero/1.0/) applies to the data made available in this article, unless otherwise stated. 


\section{Background}

Nasopharyngeal carcinoma (NPC), also known as Cantonese cancer, has a distinctive geographic variation [1-3]. It is rare worldwide, but the incidence is particularly high in North Africa and Southeast Asia, especially in Guangdong, China (for instance, Guangzhou City). The peak age of NPC is also different in high and low risk populations (high-risk: 40-55 years, low-risk: $15-24$ and 65-79 years), but the male to female ratio is $2.5-3$ to 1 across populations consistently. Tobacco is classified as a group 1 carcinogen by the International Agency for Research on Cancer (IARC). It is a well-known causal factor for head and neck cancers, except NPC.

In the past 3 to 4 decades, 43 case-control studies and 6 cohort studies (including our Guangzhou Occupational Cohort Study) have reported results on the association between tobacco use and NPC. In 2012, IARC reported a causal association of smoking with NPC based on 14 casecontrol studies and 6 cohort studies [4]. A meta-analysis [5] included 28 case-control and 4 cohort studies found a higher risk of NPC in ever-smokers than never smokers (pooled odds ratio (OR): 1.60, $95 \%$ confidence interval (CI): 1.38-1.87). However, the 2014 United States (US) Surgeon General Report [6] and the 2012 China Tobacco Hazard Report [7] were undecided on whether the association between smoking and NPC is causal.

The quality of these case-control and cohort studies varied. About two-thirds of them were conducted in low or medium risk areas. Much of the evidence came from case-control studies, which might be subject to recall bias with over-estimated odds ratios. Prospective studies reporting significant associations between smoking and NPC risk are scarce.

The Guangzhou Occupational Cohort was among the largest cohorts included in the Asia Pacific Cohort Studies Collaboration with numerous publications [8-10]. The Guangzhou Occupational Cohort has the largest number of NPC deaths in high risk areas, whereas the numbers in the other cohorts were too small for further analysis. The aim of the present paper was to examine whether baseline smoking predicted NPC mortality in Chinese adults in Guangzhou, which is a high NPC risk region.

\section{Methods}

\section{Subjects}

The Guangzhou Occupational Diseases Prevention and Treatment Center established a regular occupational health examination system to monitor the workers' health and occupational hazards [11]. Depending on their severity of occupational exposure, workers from factories, and drivers renewing their driver's license were required to undergo biannual, annual or biennial medical examinations to certify their fitness. The examination results were recorded in standardized data collection forms by physicians [12].
The Guangzhou Occupational Cohort was established from the information in the standardized forms. A total of 165,634 subjects $(129,135$ men and 36,499 women) were included from 399 factories and 11 driver examination stations from 1988 to 1992 . These factories and stations covered about 67 and $75 \%$ of all eligible factories and Guangzhou resident drivers, respectively. Hence, the whole cohort comprised of 2 subcohorts: workers $(n=82,160)$ and drivers $(n=83,474)$. Details of the methods were reported elsewhere $[11,12]$ and this cohort has contributed several publications on smoking and related mortality to the Asia Pacific Cohort Studies Collaboration [8-10].

The vital status and cause of death of all subjects were ascertained from factories, Public Health Bureau Statistics Office, funeral homes and local police stations through December, 1998 in the worker cohort and September, 1999 in the driver cohort by two physicians and double checked by a medically qualified epidemiologist [12]. During the follow up period, 95 NPC deaths (76 workers, 19 drivers) had occurred [12]. All coders were blinded to the subjects' baseline information, and the International Classification of Disease $9^{\text {th }}$ revision (ICD-9) was used to classify the causes of death [11-13].

Ethics approval (for all sites and participants) was obtained from the Ethics Committee, Faculty of Medicine, The University of Hong Kong. Permission to use data was granted by Guangzhou Occupational Diseases Prevention and Treatment Centre.

\section{Analytical cohort and exposure}

The present analysis excluded subjects who had cancers (including NPC), cardiovascular diseases, respiratory diseases and other diseases at baseline; deaths within two years; and those who had no information on daily smoking amount or duration. The final analytical cohort included 101,823 subjects $(86,269$ men and 15,554 women) (Additional file 1: Figure S1).

Information on demographic characteristics, smoking and drinking status, occupational exposures, and medical history was collected at baseline [11-13]. Data on smoking included smoking status (never smokers, occasional smokers, daily smokers and ex-smokers), number of cigarettes smoked per day, and smoking duration (years of smoking). A daily smoker was defined as one who smoked at least one cigarette per day for at least six months [11]. The numbers of occasional (5\%) and ex-smokers (0.6\%) were too small for statistical analysis and were excluded from the analysis.

Cumulative tobacco consumption (pack-years) was computed as follows: number of pack-years = (number of cigarettes smoked per day $\times$ number of years of smoking)/20 (20 cigarettes per pack). 


\section{Statistical methods}

Cox proportional hazard model was used in SPSS 20.0 to estimate hazards ratios (HRs) and $95 \%$ confidence intervals (CIs) of NPC mortality for tobacco use adjusting for age, sex, education level, drinking status, occupation and cohort status. $\mathrm{P}$ for trend was tested by regressing the smoking variables (e.g., 1 for never smokers, 2 for 1-14 cigarettes/day, and 3 for $15+$ cigarettes/day) as continuous variables in the Cox model.

Alcohol is a well-known risk factor of NPC which can modify the effect of smoking on NPC risk. [14] Therefore, interaction between smoking and drinking status was accounted for the analysis. Smoking and alcohol exposures were also stratified based on the paper by Ferreira Antunes et al. [15]. The proportional hazards assumption was checked by visual inspection of plots of $\log (-\log S)$ against time, where $S$ is the estimated survival function.

\section{Results}

In the final analytical cohort of 101,823 subjects, the total follow up was 746,159 person-years and the mean follow up duration was 7.3 years. The subjects were aged 30 to 87 years with a mean (standard deviation) age of 41.0 (5.7) years. Thirty four NPC deaths were observed (30 male deaths, 4 female deaths).

Table 1 shows that about $48 \%$ men and almost $54 \%$ women were aged 35 to 39 years. About $77 \%$ had secondary education. Almost all (93\%) were rated as healthy or fairly healthy by physicians. Daily smoking rate was $53.3 \%$ in men, but $0.6 \%$ in women. Over $80 \%$ in men and almost $98 \%$ women were never drinkers. Missing data were about $1 \%$ in all variables.

In Table 2, compared with never smokers, the crude HR of NPC mortality from smoking in daily smokers was 3.57 (95\% CI 1.66-7.65; $p=0.001$ ), the adjusted HR was 2.95 (1.01-8.68; $p=0.048)$. The crude HR for smoking 15 cigarettes or more per day was $4.52(2.01-10.14 ; p<0.001)$ and the adjusted HR was $4.00(1.29-12.35 ; p=0.016)$. Smoking for 10 years or more showed a crude HR of $3.94(1.80-8.60 ; p=0.001)$ and an adjusted HR of 2.93 (0.97-8.89; $p=0.058)$. The crude and adjusted HR for smoking more than 10 pack-years was 5.52 (2.50-12.20; $p<0.001)$ and $4.03(1.29-12.58 ; p=0.016)$, respectively. All the adjusted HRs above were accounted for smokingalcohol interaction

Significant trends suggesting increased risk with daily smoking amount ( $\mathrm{p}$ for trend $=0.01$ ) and cumulative consumption (pack-years) ( $\mathrm{p}$ for trend $=0.01$ ) were observed in the adjusted HRs of Model 1, but the trend was of borderline significance for smoking duration ( $p$ for trend $=0.06$ ) (Table 2, Model 1). Note that the HRs in the lower exposure group did not significantly different from unity.
Table 1 Characteristics of the 101,823 subjects in the Guangzhou Occupational Cohorts, at baseline (1992)

\begin{tabular}{|c|c|c|c|}
\hline & $\begin{array}{l}\text { Men } \\
N=86,269(\%)\end{array}$ & $\begin{array}{l}\text { Women } \\
N=15,554(\%)\end{array}$ & $\begin{array}{l}\text { Total } \\
N=101,823(\%)\end{array}$ \\
\hline \multicolumn{4}{|l|}{ Age, years } \\
\hline $30-34$ & $4568(5.5)$ & $993(6.4)$ & $5561(5.5)$ \\
\hline $35-39$ & $41,645(48.3)$ & $8452(54.3)$ & $50,097(49.2)$ \\
\hline $40-44$ & $21,769(25.2)$ & 4107 (26.4) & $25,876(25.4)$ \\
\hline $45-49$ & $9663(25.2)$ & $1488(9.6)$ & 11,151 (11.0) \\
\hline $50-54$ & $5033(5.8)$ & $392(2.5)$ & $5425(5.3)$ \\
\hline $55-59$ & 3077 (3.6) & $80(0.5)$ & $3157(3.1)$ \\
\hline $60+$ & $514(0.6)$ & $42(0.3)$ & $556(0.6)$ \\
\hline \multicolumn{4}{|l|}{ Marital status } \\
\hline Married & 85,247 (98.8) & $15,143(97.4)$ & 100,390 (98.6) \\
\hline Not married & $510(0.6)$ & $345(2.2)$ & $855(0.8)$ \\
\hline Missing & $512(0.6)$ & $66(0.4)$ & $578(0.6)$ \\
\hline \multicolumn{4}{|l|}{ Education level } \\
\hline Primary or below & 7440 (8.6) & $3152(20.3)$ & $10,592(10.4)$ \\
\hline Secondary & $67,405(78.1)$ & $11,073(71.2)$ & 78,478 (77.1) \\
\hline Tertiary & 10,894 (12.6) & $1222(7.9)$ & $12,116(11.9)$ \\
\hline Missing & $530(0.6)$ & $107(0.7)$ & $637(0.6)$ \\
\hline \multicolumn{4}{|l|}{ Rank } \\
\hline Cadre & 19,535 (22.6) & $3326(21.4)$ & $22,861(22.5)$ \\
\hline Worker & $65,458(75.9)$ & $12,090(77.7)$ & $77,548(76.2)$ \\
\hline Missing & $1276(1.5)$ & $138(0.9)$ & $1402(1.4)$ \\
\hline \multicolumn{4}{|l|}{ Health status } \\
\hline Healthy & 71,337 (82.7) & $11,666(75.0)$ & $83,003(81.5)$ \\
\hline Fairly Healthy & $9018(10.5)$ & $2642(17.0)$ & $11,660(11.5)$ \\
\hline Abnormal & $1332(1.5)$ & $74(0.5)$ & $1406(1.4)$ \\
\hline Unknown & $4346(5.0)$ & $1061(6.8)$ & $5407(5.3)$ \\
\hline Missing & $236(0.3)$ & $111(0.7)$ & $347(0.3)$ \\
\hline \multicolumn{4}{|l|}{ Smoking status } \\
\hline Never smokers & $40,119(46.5)$ & $15,464(99.4)$ & $55,583(54.6)$ \\
\hline Occasional smokers & $114(0.1)$ & $1(0.01)$ & $115(0.1)$ \\
\hline Daily smokers & $45,988(53.3)$ & $89(0.6)$ & $46,077(45.3)$ \\
\hline Ex-smokers & $13(0.02)$ & 0 & $13(0.01)$ \\
\hline Missing & $35(0.04)$ & 0 & $35(0.03)$ \\
\hline \multicolumn{4}{|l|}{ Drinking status } \\
\hline Never drinkers & $71,340(82.7)$ & $15,164(97.5)$ & $86,504(85.0)$ \\
\hline Occasional smokers & $6273(7.3)$ & $341(2.2)$ & $6614(6.5)$ \\
\hline Daily drinkers & $8432(9.8)$ & $43(0.3)$ & $8475(8.3)$ \\
\hline Ex-drinkers & $27(0.03)$ & 0 & $27(0.03)$ \\
\hline Missing & $197(0.2)$ & $6(0.04)$ & $203(0.2)$ \\
\hline
\end{tabular}

The joint effects of smoking and drinking observed for NPC mortality risk were assessed in Table 3 . The use of the interaction term resulted in an increase in the values 
Table 2 Hazard ratios (HRs) of NPC deaths by smoking status in the combined cohort (both sexes)

\begin{tabular}{|c|c|c|c|c|}
\hline & Total person-years of participants & $\begin{array}{l}\text { Mortality rate of NPC per 10,000 } \\
\text { person-years }(95 \% \mathrm{Cl})\end{array}$ & Crude HR (95 \% Cl) & Model 1 HR (95 \% Cl) \\
\hline Never smokers & 409,095 & $0.22(0.11-0.42)$ & 1.00 & 1.00 \\
\hline \multicolumn{5}{|l|}{ Smoking status } \\
\hline Daily smokers & 337,064 & $0.74(0.50-1.10)$ & $3.57(1.66-7.65)^{* *}$ & $2.95(1.01-8.68)^{*}$ \\
\hline \multicolumn{5}{|c|}{ Smoking amount (cigarettes/day) } \\
\hline $1-14$ & 162,244 & $0.49(0.25-0.99)$ & $2.45(0.94-6.37)$ & $1.74(0.45-6.79)$ \\
\hline $15+$ & 174,820 & $0.97(0.60-1.56)$ & $4.52(2.01-10.14)^{* *}$ & $4.00(1.29-12.35)^{*}$ \\
\hline$P$ for trend & & & $<0.001$ & 0.012 \\
\hline \multicolumn{5}{|c|}{ Smoking duration (years) } \\
\hline $1-9$ & 87,556 & $0.46(0.17-1.22)$ & $2.36(0.72-7.73)$ & $3.07(0.69-13.62)$ \\
\hline $10+$ & 249,508 & $0.84(0.55-1.29)$ & $3.94(1.80-8.60)^{* *}$ & $2.93(0.97-8.89)$ \\
\hline$P$ for trend & & & 0.001 & 0.064 \\
\hline \multicolumn{5}{|c|}{ Smoking cumulative consumption (pack-years) } \\
\hline$<10$ & 181,243 & $0.33(0.15-0.74)$ & $1.65(0.59-4.66)$ & $1.76(0.45-6.89)$ \\
\hline $10+$ & 155,821 & $1.22(0.78-1.91)$ & $5.52(2.50-12.20)^{* *}$ & $4.03(1.29-12.58)^{*}$ \\
\hline $\mathrm{P}$ for trend & & & $<0.001$ & 0.014 \\
\hline
\end{tabular}

Model 1- adjusted by age, sex, education, drinking status, cohort status \& occupation (including cadre level workers, general workers, and drivers), accounted for smoking-drinking interaction ${ }^{*} p<0.05,{ }^{* *} p<0.01$

of the HRs of almost all the smoking-related variables. However, the number of NPC deaths was small $(n=27)$ and the $95 \% \mathrm{CI}$ were wide.

The differences between the HRs in the two sub-cohorts were tested by including the interaction term of cohort status by smoking. The $p$ value for the interaction term was 0.44 , indicating that the association of smoking and NPC mortality did not vary by sub-cohort status.

\section{Discussion}

We showed that higher daily smoking amount and greater cumulative consumption being associated with higher risk of NPC mortality. An earlier paper from the Guangzhou Occupational Study showed some preliminary results of the association in 2004 [13]. However, this previous analysis only focused on the worker sub-cohort $(n=82,160)$, compared the risk between ever and never smokers and did not report dose-response results. The present study included the driver sub-cohort. We carefully used the most appropriate exclusion criteria for analysis and provided more robust and the first prospective evidence with dose-response relation from the largest cohort in an NPC endemic area.

According to the World Health Organization (WHO) [16], the 3 histological types of NPC have different distribution in high and low risk areas. Over $90 \%$ of NPC cases in high-risk areas are undifferentiated carcinoma (Type III), while squamous-cell carcinoma (Type I) is the major histologic type in low-risk areas [5, 17]. Previous studies, including a meta-analysis [5], demonstrated that the association between smoking and NPC was stronger in squamous-cell carcinoma (Type I, main cell type in lowrisk population) than that in undifferentiated carcinoma (Type III, main cell type in high-risk population) $[5,18]$. A slightly higher risk of squamous-cell NPC (pooled OR 2.20 , $95 \%$ CI 1.63-2.98) than that of undifferentiated NPC (pooled OR 1.27, 95 \% CI 0.98-1.66) was found in Xue's meta-analysis from 4 case-control studies, which might be subject to recall bias resulting in higher ORs. Studies included in the meta-analysis also had the heterogeneity problem $\left(p<0.01, \mathrm{I}^{2}=86\right)$. Unfortunately, we did not have histology data for the NPC deaths. But other studies in Guangzhou and other high-risk areas have shown that the predominant type of NPC is undifferentiated carcinoma (which accounts for $90 \%$ of cases in endemic regions) $[3,19,20]$. Our results may indicate that smoking has a stronger (than previously expected) association with NPC mortality in high-risk areas as well as those in low-risk areas.

Among all 6 cohort studies [13, 17, 18, 21-23] on smoking and NPC, Guangzhou had the highest age standardized incidence rate (ASIR) of NPC in men $(22.2 / 100,000)$ and in women $(9.9 / 100,000)$ [24], which was twice as high as those in intermediate NPC risk regions of Singapore (10.5/100,000 in men, 5.4/100,000 in women) [17] and Taiwan (9.02/100,000 in men, 2.79 in women) [25] and more than 20 times higher than those in low risk regions of the US and United Kingdom (1/100,000).

As mentioned above, only six cohort studies including the present Guangzhou cohort [13] had reported results 
Table 3 Individual and joint effects of smoking and drinking on NPC adjusted for age, sex, education, cohort \& occupational status

\begin{tabular}{|c|c|c|c|c|}
\hline Category & $\begin{array}{l}\text { Total person-years } \\
\text { of participants }\end{array}$ & $\begin{array}{l}\text { Mortality rate of NPC per 10,000 } \\
\text { person-years }(95 \% \mathrm{Cl})\end{array}$ & $\begin{array}{l}\text { No of } \\
\text { deaths }\end{array}$ & $\begin{array}{l}\text { Model } 2 \mathrm{HR} \\
(95 \% \mathrm{Cl})\end{array}$ \\
\hline \multicolumn{5}{|l|}{ Smoking and drinking status } \\
\hline Never smoker and never drinker & 390,148 & $0.21(0.10-0.41)$ & 8 & 1.00 \\
\hline Never smoker and daily drinker & 6265 & $1.60(0.22-11.33)$ & 1 & $4.19(0.47-37.22)$ \\
\hline Daily smoker and never drinker & 240,998 & $0.50(0.28-0.88)$ & 12 & $2.95(1.01-8.68)^{*}$ \\
\hline Daily smoker and daily drinker & 56,597 & $1.06(0.48-2.36)$ & 6 & $3.38(0.95-11.97)$ \\
\hline \multicolumn{5}{|l|}{ Smoking amount and drinking status (cigarettes/day) ${ }^{a}$} \\
\hline Never smoker and never drinker & 390,148 & $0.21(0.10-0.41)$ & 8 & 1.00 \\
\hline Never smoker and daily drinker & 6265 & $1.60(0.22-11.33)$ & 1 & $4.49(0.51-39.90)$ \\
\hline Level 1 smoking amount and never drinker & 125,001 & $0.32(0.12-0.85)$ & 4 & $2.15(0.56-8.18)$ \\
\hline Level 1 smoking amount and daily drinker & 21,113 & / & 0 & / \\
\hline Level 2 smoking amount and never drinker & 115,997 & $0.53(0.28-1.02)$ & 8 & $3.55(1.12-11.31)^{*}$ \\
\hline Level 2 smoking amount and daily drinker & 35,485 & $1.28(0.58-2.86)$ & 6 & $4.86(1.34-17.61)^{*}$ \\
\hline \multicolumn{5}{|l|}{ Smoking duration and drinking status (years) ${ }^{b}$} \\
\hline Never smoker and never drinker & 390,148 & $0.21(0.10-0.41)$ & 8 & 1.00 \\
\hline Never smoker and daily drinker & 6265 & $1.60(0.22-11.33)$ & 1 & $4.21(0.47-37.41)$ \\
\hline Level 1 smoking duration and never drinker & 71,958 & $0.42(0.13-1.29)$ & 3 & $3.52(0.81-15.34)$ \\
\hline Level 1 smoking duration and daily drinker & 9877 & / & 0 & / \\
\hline Level 2 smoking duration and never drinker & 169,040 & $0.53(0.28-1.02)$ & 9 & $2.67(0.87-8.23)$ \\
\hline Level 2 smoking duration and daily drinker & 46,720 & $1.28(0.58-2.86)$ & 6 & $3.61(1.01-12.93)^{*}$ \\
\hline \multicolumn{5}{|l|}{ Smoking cumulative consumption and drinking status (pack-years) ${ }^{c}$} \\
\hline Never smoker and never drinker & 390,148 & $0.21(0.10-0.41)$ & 8 & 1.00 \\
\hline Never smoker and daily drinker & 6265 & $1.60(0.22-11.33)$ & 1 & $4.65(0.52-41.41)$ \\
\hline Level 1 smoking cumulative consumption and never drinker & 143,711 & $0.28(0.10-0.74)$ & 4 & $2.10(0.55-8.11)$ \\
\hline Level 1 smoking cumulative consumption and daily drinker & 22,306 & / & 0 & / \\
\hline Level 2 smoking cumulative consumption and never drinker & 97,286 & $0.82(0.41-1.64)$ & 8 & $3.69(1.15-11.82)^{*}$ \\
\hline Level 2 smoking cumulative consumption and daily drinker & 34,291 & $1.75(0.79-3.89)$ & 6 & $4.77(1.30-17.50)^{*}$ \\
\hline
\end{tabular}

Model 2 - adjusted for age, sex, education, cohort \& occupational status with smoking and alcohol interaction terms ${ }^{*} p<0.05$

aLevel 1: smoked 1-14 cigarettes per day, Level 2: smoked more than 15 cigarettes per day

b Level 1: 1-9 years of smoking duration, Level 2: more than 10 years of smoking duration

'Level 1: less than 10 pack-years of smoking cumulative consumption, Level 2: more than 10 pack-years of smoking cumulative consumption

on NPC and tobacco use [17, 18, 21-23]. Among the two cohort studies conducted in low-risk areas, only the one from the US [18] reported a significant trend with daily smoking amount, but this study did not find a significant trend for smoking duration and did not report results on cumulative consumption. The other study from the British doctors cohort [23] did not report any significant results because of the small number of NPC $(n=4)$. In endemic areas, two cohort studies in Taiwan $[21,22]$ and one cohort study in Singapore [17] reported a significant increase in NPC risk in heavy and chronic smokers, but only the Singapore study showed a doseresponse relation by smoking duration, whereas the two Taiwan studies did not show any significant trends.

Our results have provided new prospective evidence that heavy and chronic smokers had significantly increased risk of NPC mortality, which are consistent with most casecontrol studies and the 4 cohort studies from Taiwan, Singapore and the US $[5,17,18,22]$. The adjusted HR from our study was 3.26 (1.14-9.36) in heavy smokers who smoked more than 15 cigarettes per day, which was consistent (with overlapping $95 \% \mathrm{CI}$ ) with that of 3.3 (0.8-14.0) from Liaw et al. in Taiwan. We observed significant trends suggesting a dose-response relation for daily smoking amount, which was consistent with the findings from the US cohort study. [18] Moreover, our study was the first to observe a significant trend suggesting dose-response relation for cumulative tobacco use among all cohort studies above. But the limited number of NPC deaths restricted our grouping of exposure levels (only three exposure levels). The significant trends might be due to the large HRs in the group with the greatest exposure. 
Because the HRs in the low exposure group did not significantly different from unity, a threshold level below which smoking is not associated with increased risk is possible and cannot be ruled out from our study. Future studies with larger sample size are needed to confirm our findings.

Compared with other cohort studies, our study used lower smoking level to define heavy and chronic smokers (more than 10 pack-years, more than 10 years smoking or 15 cigarettes per day), but our results still showed a stronger and significant association between smoking and NPC mortality. Despite the different definitions of heavy exposure, our results are consistent with those of the metaanalysis by Xue et al. [5].

We recognize the limitations of the small number of NPC deaths (especially in women) and the wide $95 \%$ confidence intervals of the risk estimates, the lack of data on nonfatal new cases and the short follow-up. However, there was only one cohort study [18] which had more NPC deaths $(n=48)$ than ours. We are now planning for a further follow-up of the cohort.

Because alcohol consumption and smoking are important NPC risk factors [14], alcohol status and smokingdrinking interaction were accounted for in the present analysis. The $p$ value for the smoking-drinking interaction was 0.26 , which was not significant. The use of smoking and alcohol interaction term resulted in an increased in HRs for combined exposure of alcohol intake and smoking HRs, which suggested an interaction between smoking and drinking, but the $95 \%$ CIs were very wide. Due to the small event number, we cannot fully investigate the joint effects of smoking and drinking and the risk of NPC. Further investigations with more NPC deaths are needed. Although we suspect some drivers did not disclose their drinking habit or under-reported their consumption during the driver license renewal, the results were similar after including alcohol data.

Sensitivity analysis without female subjects and alcohol adjustment were performed in Additional file 1: Table S1. The results of the sensitivity analyses were similar to the main results above.

In the present analysis, we excluded subjects with NPC or other diseases at baseline to reduce bias from reverse causation (people with NPC or diseases would be more likely to quit smoking). These strict exclusion criteria probably allowed the better detection of the association with smoking in the analysis.

Despite its declining incidence and mortality in the past decades [2], NPC is still among the top 10 common cancers in epidemic areas, such as Guangzhou [26] and Hong Kong [27]. The present study should provide convincing new evidence to support causal inference on the association of smoking with NPC mortality.

China is still in the second stage of tobacco epidemic [28], and tobacco control is a major public health concern.
Guangdong not only has the most high-risk population of NPC, but also has a large number of smokers in China (about 16 million, based on the estimated smoking prevalence by $\mathrm{Su}$ et al.) [29]. Due to the time gap between smoking and disease occurrence, the consequences of tobacco use in smokers will continue to expand, including NPC if the association is causal. Tobacco control in high NPC risk areas, including smoking cessation, should have additional benefits in reducing NPC.

Further follow-up of the present cohort, including fatal and nonfatal NPC is warranted. There are many cohort studies in China mainland in the Asia Pacific Cohort Studies Collaboration and elsewhere which can be used for further follow-up and analysis. Detailed analyses, including meta-analyses based on pooled individual data are low cost studies to examine smoking and other risk factors of NPC. Information on the histological types of NPC, which is often lacking in most cancer registries and NPC epidemiological studies, is essential to estimate the histology-specific risk of NPC for smoking, and its interaction with other risk factors (such as EB virus) and to study the mechanisms of carcinogenesis.

\section{Conclusions}

In our study, heavier and chronic smokers had significantly higher risk of NPC mortality. Significant trends suggesting dose-response relationships of smoking amount and smoking cumulative consumption and the risk of NPC mortality were observed in our study, but more prospective cohorts with more NPC deaths are required to confirm our results, or to examine whether there is a threshold level of exposure, which has important implications for cancer prevention. The results from this first and largest prospective study in a high NPC risk region support that smoking is one of the risk factors likely to be causally associated with NPC mortality. Strong tobacco control measures are needed to motivate smokers to stop smoking.

\section{Additional file}

Additional file 1: Table S1. Hazard ratios (HRs) of NPC deaths by smoking status in the combined cohort (men). Figure S1: The flow chart of the analytical cohort selection in Guangzhou Occupational Cohort (GZOC). (DOCX 29 kb)

\section{Abbreviations}

NPC: Nasopharyngeal carcinoma; HR: Hazard ratio; IARC: International Agency for Research on Cancer; OR: Odds ratio; Cl: Confidence interval; US: United States; WHO: World Health Organization; ASIR: Age standardized incidence rate.

\section{Competing interests}

The authors declare that they have no competing interests.

\section{Authors' contributions}

JHL and CML conducted data analysis. SYH, CQJ, WSZ and THL participated in the cohort design, data collection and data cleaning. LX and ZMM contributed to the analysis and interpretation of the data. JHL drafted the 
manuscript under THL and CML's supervision. SYH, WSZ, LX, CQJ and ZMM helped to draft the manuscript and revised it critically for important intellectual content. All authors read and approved the final manuscript.

\section{Acknowledgements}

This study was funded by the Hong Kong Research Grants Council (HKU 466/ 96 M), Hong Kong Health Services Research Committee (531036), Guangdong Province Public Health Bureau Five One Project (96-186), Guangzhou Municipal Science and Technology Commission (96-Z-65), Hong Kong RGC Area of Excellence Scheme (AoE/M-06/08), World Cancer Research Fund UK (WCRF UK) and Wereld Kanker Onderzoek Fonds (WCRF NL), as part of the WCRF International grant programme (2011/460).

We also wish to thank Dr. Lai-Ming Ho for his statistical support.

\section{Author details}

'School of Public Health, University of Hong Kong, No 21 Sassoon Road, Hong Kong, China. ${ }^{2}$ Guangzhou Occupational Diseases Prevention and Treatment Center, No 1 Tianqiang Street, Huang Pu Road West, Tianhe District, Guangzhou 510620, China.

Received: 30 August 2015 Accepted: 3 November 2015 Published online: 16 November 2015

\section{References}

1. Lau HY, Leung CM, Chan YH, Lee AW, Kwong DL, Lung ML, et al. Secular trends of salted fish consumption and nasopharyngeal carcinoma: a multijurisdiction ecological study in 8 regions from 3 continents. BMC Cancer. 2013;13:298. doi:10.1186/1471-2407-13-298.

2. Lee AW, Ng WT, Chan YH, Sze H, Chan C, Lam TH. The battle against nasopharyngeal cancer. Radiother Oncol. 2012;104(3):272-8. doi:10.1016/ j.radonc.2012.08.001.

3. Cao SM, Simons MJ, Qian CN. The Prevalence and Prevention of Nasopharyngeal Carcinoma in China. Chin J Cancer. 2011;30(2):114-9. doi:10.5732/cjc.010.10377.

4. Habits P, Combustions I. 2012/12/01 ed. IARC Monogr Eval Carcinog Risks Hum, vol Pt E. Lyon: International Agency for Research on Cancer; 2012.

5. Xue WQ, Qin HD, Ruan HL, Shugart YY, Jia WH. Quantitative association of tobacco smoking with the risk of nasopharyngeal carcinoma: a comprehensive meta-analysis of studies conducted between 1979 and 2011. Am J Epidemiol. 2013;178(3):325-38. doi:10.1093/aje/kws479.

6. Warren GW, Alberg AJ, Kraft AS, Cummings KM. The 2014 surgeon jeneral's report: "The health consequences of smoking-50 years of progress": a paradigm shift in cancer care. 2014;120(13):1914-6. doi:10.1002/cncr.28695.

7. China Ministry of Health. [China tobacco hazard report] 2012.

8. Ansary-Moghaddam A, Martiniuk A, Lam TH, Jamrozik K, Tamakoshi A, Fang $X$, et al. Smoking and the risk of upper aero digestive tract cancers for men and women in the Asia-Pacific region. Int J Environ Res Public Health. 2009;6(4):1358-70. doi:10.3390/ijerph6041358.

9. Kengne AP, Nakamura K, Barzi F, Lam TH, Huxley R, Gu D, et al. Smoking, diabetes and cardiovascular diseases in men in the Asia Pacific region. J Diabetes. 2009;1(3):173-81. doi:10.1111/j.1753-0407.2009.00028.x.

10. Woodward M, Lam TH, Barzi F, Patel A, Gu D, Rodgers A, et al. Smoking, quitting, and the risk of cardiovascular disease among women and men in the Asia-Pacific region. Int J Epidemiol. 2005;34(5):1036-45. doi:10.1093/ije/dyi104.

11. Lam TH, Jiang CQ, Ho SY, Zhang WS, Liu WW, He JM. Smoking and mortality in 81,344 drivers in Guangzhou, China. Occup Environ Med. 2002;59(2):135-8.

12. Ho SY, Lam TH, Jiang CQ, Zhang WS, Liu WW, He JM, et al. Smoking, occupational exposure and mortality in workers in Guangzhou, China. Ann Epidemiol. 2002;12(6):370-7.

13. Zhang WS, Jiang CQ, Lam TH, Ho SH, Chen Q, Liu WW, et al. A prospective cohort study on the comparison of risk of occupational dust exposure and smoking to death. Zhonghua Liu Xing Bing Xue Za Zhi. 2004;25(9):748-52.

14. Chen LWGL, Byyd-Lindsley K, Tao XG, Robinson K, Lam TK, Herman J, et al. Alcohol consumption and the risk of nasopharyngeal carcinoma: a systematic review. Nutr Cancer. 2009;61(1):1-15.

15. Antunes JLFTT, Biazevic MGH, Boin AF, Scully C, Petti S. Joint and independent effects of alcohol drinking and tobacco smoking on oral cancer: a large case-control study. PLoS One. 2013;8(7):e68132.
16. Thompson LDR. Update on nasopharyngeal carcinoma. Head Neck Pathol. 2007;1(1):81-6. doi:10.1007/s12105-007-0012-7.

17. Friborg JT, Yuan JM, Wang R, Koh WP, Lee HP, Yu MC. A prospective study of tobacco and alcohol use as risk factors for pharyngeal carcinomas in Singapore Chinese. Cancer. 2007;109(6):1183-91. doi:10.1002/cncr.22501.

18. Chow WH, McLaughlin JK, Hrubec Z, Nam JM, Blot WJ. Tobacco use and nasopharyngeal carcinoma in a cohort of US Veterans. Int J Cancer. 1993;55(4):538-40.

19. Tse LA YT, Mang WK, Wong SL. Incidence rate trends of histological subtypes of nasopharyngeal carcinoma in Hong Kong. Br J Cancer. 2006;95:1269-73.

20. Tao XTJ, Gu M, Liu L, Wei W, Yang H. Recurrent nasopharyngeal carcinoma: a clinical dilemma and challenge. Curr Oncol. 2013;20(5):e406

21. Liaw KM, Chen CJ. Mortality attributable to cigarette smoking in Taiwan: a 12-year follow-up study. Tob Control. 1998;7(2):141-8.

22. Hsu WL, Chen JY, Chien YC, Liu MY, You SL, Hsu MM, et al. Independent effect of EBV and cigarette smoking on nasopharyngeal carcinoma: a 20-year followup study on 9,622 males without family history in Taiwan. Cancer Epidemiol Biomarkers Prev. 2009;18(4):1218-26. doi:10.1158/1055-9965.epi-08-1175.

23. Doll R, Peto R, Boreham J, Sutherland I. Mortality from cancer in relation to smoking: 50 years observations on British doctors. $\mathrm{Br} J$ Cancer. 2005;92(3):426-9. doi:10.1038/sj.bjc.6602359.

24. Cao KJFQ, Liu YL, Huang R, Yin CD, Ma GS. Cancer incidence and mortality in Guangzhou City from 2000 to 2002. Ai Zheng. 2008;27(3):225-30.

25. Bureau of Health Promotion Department of Health, Executive Yuan. [Cancer registry annual report, 2003, Taiwan] 2007.

26. Zhou Q. [1/4 of Guangzhou citizen die of cancer]. Guangzhou Center for Disease Control and Prevention. 2014. http://www.gzcdc.org.cn/News/ View.aspx?id=1437. Accessed: 06 November 2015.

27. Top Ten Cancers in 2012 [database on the Internet]. Hong Kong Cancer Registry. 2012. Available from: http://www3.ha.org.hk/cancereg/Statistics.html. Accessed: 04 May 2015

28. Shafey ODS, Guindon GE. Tobacco control country profiles 2003. Atlanta: American Cancer Society; 2003.

29. Su SH, Su YP, Yin XF, Qin ZG, Zou XT, Tang J. Analysis on active smoking state of male residents in Guangdong province. Chin J Health Educ. 2008;24(9):706-709, 715.

\section{Submit your next manuscript to BioMed Central and take full advantage of:}

- Convenient online submission

- Thorough peer review

- No space constraints or color figure charges

- Immediate publication on acceptance

- Inclusion in PubMed, CAS, Scopus and Google Scholar

- Research which is freely available for redistribution 